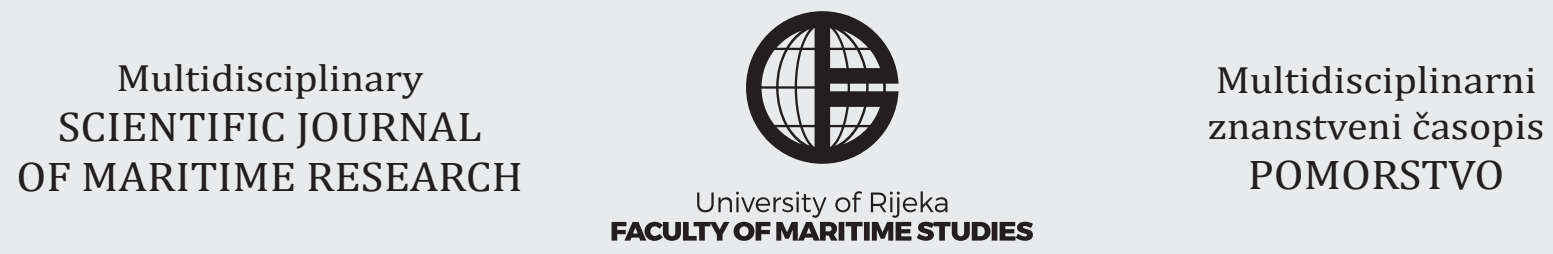

\title{
The Possibilities of Applying Blockchain Technology in Shipping
}

\author{
Alen Jugović ${ }^{1}$, Juraj Bukša², Alex Dragoslavićc ${ }^{1}$, David Sopta ${ }^{3}$ \\ ${ }^{1}$ University of Rijeka, Faculty of Maritime Studies, Studentska 2, 51000 Rijeka, Croatia \\ ${ }^{2}$ Adriatic Croatia International Club - ACI d.d., Rudolfa Strohala 2, 51000 Rijeka, Croatia, e-mail: juraj.buksa@aci-club.hr \\ ${ }^{3}$ Jadrolinija d. d., Riva 16, 51000 Rijeka, Croatia
}

\section{ABSTRACT}

Blockchain technology is a decentralized database which stores the registry of property and transactions using a peer-to-peer network, secured by cryptography, and over time, its history is locked into blocks of data which are cryptographically connected and secured. The blockchain technology was primarily designed for application in cryptocurrency transactions and related digital agreements. Due to its immutable and infallible record of all transactions within the network, the potential of this technology for broad application has been recognized. This paper analyzes the possible advantages of applying blockchain technology in logistics and maritime transport.

\section{ARTICLE INFO}

\section{Review article}

Received 19 November 2019

Accepted 19 December 2019

Key words:

Blockchain technology

Shipping

Transport chain

\section{Introduction}

The blockchain (chain of blocks) represents a distributed structure of data, i.e. a list of digital information shared between all nodes participating in the system [1]. The principal features of the blockchain are:

- the chain is structured according to the peer-to-peer model

- it is entirely decentralized, which means there is no need for a central authority

- each new entry is distributed among a multitude of nodes almost in real time

- cryptography is used for identifying participants in the system, verifying their credentials, authentication and, in some cases, exercising the right to read/write

- system nodes can add and read data into and from the blockchain, and

- there is a developed mechanism which disables making changes to data once entered into the blockchain or at least enables easy detection of any data changes.

The blockchain is used as a shared database which eliminates the role a third party plays in transaction processes and information sharing in many ways. Technology, stock, contracts, payments and other data are shared directly between the parties using encoded connections. The blockchain eliminates the roles traditionally played by banks, brokerage companies or other intermediaries.

\section{Background}

Shipping, albeit a traditional business, has successfully adapted to all new technologies throughout history, so all the advantages of information technology have been accepted very quickly. Globalization has opened new trading routes, information technology has expedited trading methods and the demand for shipping services has increased the volume of goods transported by sea. According to data provided by UNCTAD [2], 55 billion tons of cargo have been transported in 2015, with an anticipated growth of 92 billion tons by 2024. Transport and logistics costs have increased accordingly. In the United States alone, transport and logistics expenditure in 2015 amounted to over USD 1.48 trillion, which is close to $10 \%$ of the GDP [3]. Problems in the transport chain are becoming more and more evident. The non-existence of a single communications platform prevents the participants from communicating and cooperating efficiently. The majority 
of transport service providers, carriers, governments, customs declarants and freight forwarders are using obsolete methods of tracking the goods. According to KPMG, the international auditing company of Klynveld, Peat, Marwick and Goerdeler, $40 \%$ of the world's manufacturers do not have transparent data and material visibility of its entire stock [4].

The blockchain can change and improve shipping and benefit all participants in the transport process - importers, exporters, carriers, ship operators and even governments. One of the main advantages of implementing blockchain in shipping is the reduction of administrative procedures. For international shipments, companies and customs officers are compelled to fill out over 20 different kinds of paper documents to have the goods transported from the exporter to the importer and vice-versa. Most of these documents does not provide visibility in real time and data quality, which often leads to obstacles in financial reconciliation.

On a global level, on a daily basis, shipping generates around 100-120 million data which cannot be efficiently collected and analyzed using existing technology. Blockchain then presents itself as a solution because of the possibility to place key information in one place and to create a single platform for solution providers, for all the participants in the supply chain [5].

By tracking the cargo (shipment) in real time using the blockchain technology, shipping companies and ports can plan ahead for land manipulation, thus expediting the terminal operation and reducing costs. They can also use the data for quantitative predictions which improve their business operations and increase efficiency. The blockchain can secure the integrity of all entries, reducing the risk of damage or disappearance of shipments [6]. By replacing the electronic communications system with the blockchain, all parties involved have access to information, which facilitates efficient planning of operations, provides savings and secures the integrity of all entries, by reducing the risk of damage or disappearance of shipments. Information stored on the blockchain cannot be deleted or edited without leaving a trace, whereby transparency is gained and security is enhanced. The advantages offered by the blockchain technology are also interesting because of the sophisticated data encryption, which greatly reduces the risk of cyber-crime, dishonest and disloyal competition, whereby a fairer deal is secured for all parties involved.

\section{The Principal Features of Applying the Blockchain Technology}

The blockchain technology consists of two important technological components. One component is represented by hash values, and the other by cryptography. Hash values are produced based on bits and bytes comprising a piece of data. In order to transform a piece of data into a number of fixed length, the so-called hash function [7] is required. Those functions are small computer programs which enable the transformation of any piece of data (regardless of the input size) into a number of fixed length. To preserve data discretion, the Secure Hash Algorithm - SHA is used, which is a cryptographic marking function. SHA-256 is a common algorithm which generates a quasi-unique hash with a fixed, 256-bit (32-bit) size. As explained by Laurence [8, p. 10], a hash can be seen as a digital fingerprint used to lock a piece of data in a certain place within the block.

\subsection{Smart Contracts}

For a new technology to be accepted in the business world, and particularly in the traditional shipping world, it must be secure in its transparency towards business partners and protected against unwanted interferences.

Blockchain technology has already practically confirmed the above conditions by supporting the cryptocurrency system. The initial skepticism and opposition of traditionalists when it comes to investing their tangible money into something virtual (bitcoin) is declining, inversely proportional to the increase of cryptocurrency value. In shipping, it is affirmed through "Smart Contracts".

A smart contract is a computer program within the blockchain which contains a set of rules agreed upon by the parties involved in a mutual transaction. The smart contract defines the terms and conditions, rights and obligations the parties consent to. The agreement is pre-defined and written in digital and machine-readable form. A computer can automatically perform the rights and obligations stated in the smart contract as soon as the parties involved reach an agreement and meet its terms. Smart contracts facilitate self-checks and automatically impose negotiations and performance of the agreement. The advantages of smart contracts are [8, p. 193]:

- Reduction of costs - as a result of eliminating a long chain of intermediaries. Smart contracts set up relationships between people, organizations and assets without the participation of intermediaries. Smart contracts have a built in system to automatically confirm the fulfillment and perform the agreed terms whenever the pre-defined rules have been complied with. Therefore, smart contracts radically reduce transaction costs in reaching an agreement, formalization and performance.

- Speed and accuracy - all the terms in smart contracts expressly record details. A computer code is more accurate and precise than the clauses in a traditional contract. In this way, smart contracts avoid the pitfalls of manually filling in a large quantity of paper forms. Smart contract are automated and they execute and follow transactions independently in real time, which decreases/eliminates the time required to handle paperwork, making adjustments and corrections which are often needed in manually filled in documents. 
- Transparency and trust - the pre-defined terms in smart contracts are entirely visible and available to all relevant parties. Therefore, there is no room for miscommunications or misinterpretations after the contracts are concluded and there is no need to question whether a contract has been manipulated for personal gain.

- Security and storage - records of all transactions under a smart contract are encrypted and permanently stored in the blockchain, and difficult to modify. Like any other records, they are connected by hashes and the entire chain has to be replaced to modify an individual transaction.

Smart contract work according to the if-then principle, which incentivizes production - if the goods are delivered on time and in line with payments, the contract terms remain unchanged [9]. The supply chains are too often disrupted by paper documents, where forms have to travel through many approval channels, leaving them exposed to losses and fraud. Blockchain avoids this by providing everyone in the chain with a secured, available digital version and automatization of tasks and payments. Smart contracts automate the processes which are bureaucratically necessary to complete the transport.

\subsection{TradeLens - digital supply chain}

One example of implementing blockchain technology is the TradeLens global commercial blockchaim platform developed by IBM and Maersk. It provides assistance from third party solution providers to determine what is known as organizational identity for subjects participating in the platform [10]. TradeLens uses Digital Bazaar software (Blacksburg, Virginia), which develops identity management and payment solutions for companies based on the blockchain.

The cooperation between IBM and Maersk on the TradeLens project has laid a foundation for the digital supply chain, which poses challenges to many old industries and enables all members of the ecosystem to benefit from its adoption. In links everyone into the supply chain - including ship operators / BCO, freight forwarders, land transport, ports and terminals, overseas carriers, customs and state authorities - on a platform based on blockchain with security clearance and identity framework that enable [7]: instant, impeccable and secure sharing of information, by creating an efficient supply chain with transparent information for all parties in trade. Furthermore, TradeLens enables the digitalization and automatization of organizational business processes integrated in global trade, including import and export clearances, by providing security, auditing data and irreversible transactions. TradeLens can be perceived through three basic components [11]:

- Network - the basis of TradeLens is its business network - shippers, freight forwarders, ports and ter- minals, overseas carriers, state authorities, customs agents and others, which together generate a multitude of information that can be tracked, stored and shared throughout the ecosystem. This can be done any time during the life cycle of the goods in transport.

- Platform - the platform component is at the top of the data network and presents itself as a dynamic, functional medium. This open platform is supported by Hyperledger technology blockchain fabric, by creating a final audit trail of a significant shipment of information and a secure route for critical documents sharing.

- Applications and Services - the final component of applications and services uses the network and platform capacities, enabling the creation of a market which will serve the needs of the entire TradeLens ecosystem by offering an open medium anyone can build on, which can be used by anyone and where anyone sell applications to their customers who need the ecosystem now or in the future.

Image 1 shows a graphic of the components, looking upward: network, platform, applications and services.

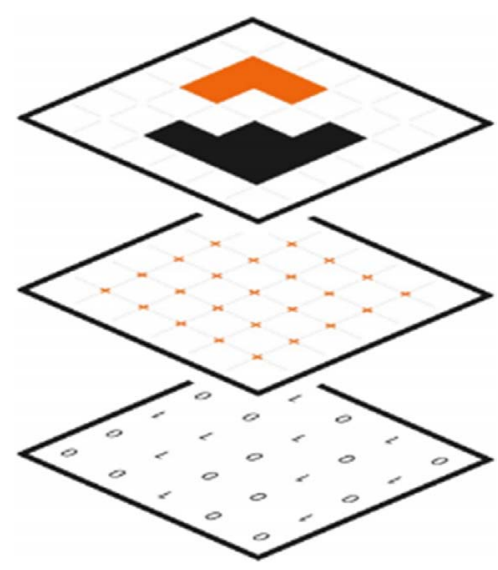

Image 1 TradeLens Component

Source: https://www.tradelens.com

Each component plays a specific role in enabling the TradeLens user to secure the highest benefit for its business.

\subsection{Ecosystem or Network}

The ecosystem ${ }^{1}$ or the Trade Lens network consists of all parties in the shipping process, joined together for sharing a unique, detailed view of the global supply chain. That means that diverse, previously fragmented organizations and government agencies will no longer have blind

\footnotetext{
The term ecosystem, in the context of the functioning of the TradeLens platform, is a personification which breathes life into the transport change
} 
sports that currently exist during the shipping life cycle by providing instantaneous value and truth of information sharing to partners in the global supply chain.

Subjects of the supply chain include overseas carriers, domestic carriers, terminal operators, ports, customs officers and even software programmers. All the members enjoy the advantages of TradeLens in different ways. For example, logistics services providers and the authorities benefit from the standard approach to the exchange of information and the platform for future innovations. The ecosystem of the TradeLens network comprises [11] :

1. Carriers - it minimizes reloading time and also reduces waiting time through better planning for the terminal's capacities by using instant information on events in real time (e.g. confirmation of the ship's actual arrival time). Additional time loss can occur due to changes in the terms or inaccurate information provided by other members of the ecosystem, such as BCOs, overseas carriers or terminals (e.g. Morski terminali), so carriers route the empty running to different locations using EOD communication via e-mail, which causes delays and inefficiencies. A common, integral platform provides a unique standard source for the supply chain and visibility of information about the event.

2. Ship Operators - communication with terminals happens online, reducing integration costs and supporting certain terminals, warehouses and inland carriers, increasing the flexibility when it comes to selecting and connecting new service providers. By connecting with the TradeLens platform, carriers can exchange more complete and detailed events concerning the shipment in real time, including events directly from shipping, intermodal transport, customs and 3PLs. Notifications are simplified by using a standardized interface on the platform. E-solutions platform for operator support enables the buyers to use it independently for tracking or subscribe to tracking events in their internal system.

3. Intermediaries - Manual collection of data from different sources and in different formats is expensive. This is a standardized, complete platform which provides a single standard source for the supply chain. Total visibility enables faster and improved service to customers. The time required to correct mistakes in paperwork is significantly reduced by linking the original documents with customs declarations through a secure audit trail.

4. Terminals - The development and support of EDI integration from point to point with shipping lines and port communities is expensive. The cost of connecting with lines and the broader port community is simplified and reduced by using the influence of industrially standard platform participants already connected to the platform. Fast, simple electronic communication ETA and ETD for all ports in the community improves the exploitation of port assets.
5. Insurance - All parties share the same version of all necessary data which ensures data consistency. This enables the simplification of business processes. Information trapped on the TradeLens platform are immutable and permanently available, allowing for a better risk analysis and business intelligence. Access to data on events allows for the analysis of trends through the network, which in turn enables the risk assessment procedure. Paper Bills of Lading are expensive and cannot be efficiently managed. CargoX are e-Bills of Lading on the blockchain, a type of smart contracts on the blockchain from ethereum, and they reduce the risk of fraud and increase the speed and flexibility for cargo owners.

6. Regulators - Unnecessary interventions or "falsely positive suggestions" due to belated and missing information. More complete information, available earlier and with better resources enable better targeting and more efficient decisions on which containers to check. The BCOs are willing to share their information facing minor delays due to inspections. Classic paperwork is reduced and a higher degree of automatization is made possible, thus enabling the authorities to focus on critical activities such as targeted risk assessments.

TradeLens offers a neutral platform which is available to the whole industry. This approach offers an excellent foundation for all main participants of logistics and freight forwarding. TradeLens blockchain is a shared, immutable record recording the transactions and tracking assets, whether tangible (container) or intangible (commercial invoice).

\section{The Potential of Blockchain Technology in Shipping}

Its potential in the global supply chain specifically depends on the following: The format of design of the blockchain and tracking options provide a complete audit, which improves the consistency of LD networks and increases the company's trust in the authenticity and quality of the product. Public or private consumers can track every product transferred through authorized platforms protected by blocks and confirm or reject the product and the participant involved. The blockchain can easily find and correct all problems by creating an irreversible audit trail. In the following image, we can see the bottlenecks of supply chains and certain solutions offered by the blockchain technology.

The blockchain's ability to record the origin of assets, transfer of ownership, legality and security requirements in real time removes uncertainties and increases accountability. Given that such systems can provide transparent data in real time, low procedural costs and a high likelihood of a fair judgment, disputes can be resolved in a fraction of time. Besides, smart contracts can automatically initiate compensation or fines if the previously agreed 


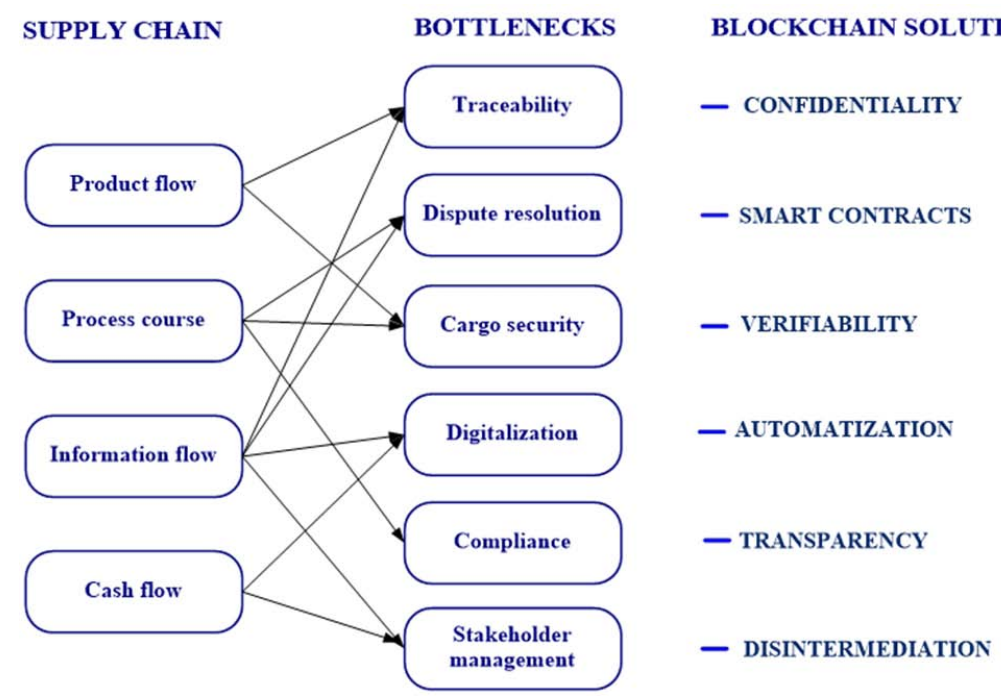

Image 2 Supply Chain Bottlenecks

Source: according Fr8 Network [4]

terms are breached. This makes complicated and lengthy dispute resolution a thing of the past.

Blockchain technology is very secure because [12]: each participant will enter into a transaction without an intermediary or any third party to be trusted in confirming the transaction. Establishing trust is based on cryptography, distributed books and the blockchain consensus. All encrypted transactions are distributed to all relevant participants. Consensus is reached so that all participants must agree to the same version of the record.

\section{Conclusion}

Using the blockchain has its weaknesses because it is a new technology and lacking in public knowledge and even expert knowledge, which makes it difficult to have a strategic vision of the true future potential. Currently there are issues with the quantity of data in the system, security of smart contracts and adoption of the technology by the users. These are the principal reasons why blockchain technology is insufficiently used.

Therefore, it is important to quickly understand and comprehend all the benefits which can change business and the world in the near future. Being an old industry, shipping will be intensely impacted by the implementation of a new technology. The automatization through smart contracts, the transparency through a decentralized system and immutable records guaranteeing security are things that will fundamentally change the whole industry - for the better. The entire blockchain concept is ideal for a transport chain, shipping included. A highly competitive industry, where new technology can save time through automated contracts and exclude the possibility of human error, offering transparency to all participants of the shipping process - which enables each buyer to verify the origin and trace the product it has bought. The savings achieved through a decentralized network and proof of work mechanisms where no third party is needed to verify and information or document. The issue of security, which will become the most important issue in shipping in the decades to come because of the arrival of automated ships. With a decentralized, encrypted network which provides security from cyber-attacks and also protects data of logistics conglomerates. Based on the research carried out and results obtained in this paper, the conclusion is that shipping is facing one of the biggest transformations in business.For blockchain projects to function, they must have a larger number of users - decentralization. Programmers and companies working on blockchain solutions must actively involve policy creators to ensure appropriate regulation and useful legislation.

\section{References}

[1] Business Insider, "3 logistics challenges to going global and how to address them," 147 2016. [Mrežno]. Available: https://www.businessinsider.in/3-logistics-challenges-togoing-global---and-how-to-address-them/articleshow/53215860.cms. [Pregledano 23. 11. 2019]. [5]

[2] Cerasis, "Where Do We Go From Here? Taking a Look at the 2016 State of Logistics Report," 2016. [Mrežno]. Available: https://cerasis.com/2016-state-of-logistics/. [Pregledano 23. 11. 2019]. [3]

[3] E. Johnson, "Blockchain platform TradeLens seeks 'organizational identity'," JOC, 12. 9. 2019. [Mrežno]. Available: https://www.joc.com/technology/blockchain-platformtradelens-seeks-'organizational-identity'_20190912.htm. [Pregledano 23.11. 2019]. [10]

[4] G. Thistlethwaite, "IBM \& Maersk Launch TradeLens Blockchain Shipping Platform," Geneva business news, 17. 8. 2018. [Mrežno]. Available: https://www.gbnews.ch/ibm- 
maersk-launch-tradelens-blockchain-shipping-platform/. [Pregledano 23. 11. 2019]. [6]

[5] Kišić, "Pregled primjene blockchain tehnologije: perspektiva organizacije i menadžmenta," Zbornik radova Međimurskog veleučilišta u Čakovcu, svez. 9, br. 1, pp. 41-45, 2018. [7]

[6] M. Swan, Blockchain: Blueprint for a New Economy, Sebastopol: O’Reilly Media, 2015. [12]

[7] M. Rajarshi, "Smart Contracts: Die Blockchain-Technologie, die Anwälte ersetzen wird," Blockgeeks, 2 2019. [Mrežno]. Available: https://blockgeeks.com/guides/de/smart-contracts-die-blockchain-technol. [Pregledano 23. 11. 2019]. [9]

[8] S. Brakeville, S. Balaj i Y. Spekto, "Realigning Consciousness with the logistics industry," Fr8 Network, 2018. [Mrežno]. Available: https://fr8.network. [Pregledano 23.11. 2019]. [4]
[9] Radanović i R. Likić, "Mogućnosti upotrebe blockchain tehnologije u medicini," Bilten Hrvatskog društva za medicinsku informmatiku, svez. 25, br. 1, pp. 30-40, 2019. [13]

[10] S. Šijanović Pavlović, A. Bolanča i D. Pavlović, “"Internet of Things” i „Blockchain” kao alati razvoja fleksigurnog energetskog sektora," Nafta i plin, svez. 38, br. 253, pp. 107-117, 2018. [1]

[11] T. Laurence, Blockchain for Dummies, Hoboken: John Wiley \& Sons, Inc., 2017. [8]

[12] Tradelens, "Digitizing the global supply chain," Tradelens, 2019. [Mrežno]. Available: https://www.tradelens.com. [Pregledano 2311 2019]. [11]

[13] UNCTAD, “The Review of Maritime Transport," United Nations Publications, New York, 2018. [2] 